\title{
Emergence of the Pre-Bötzinger Respiratory Rhythm Generator in the Mouse Embryo
}

\author{
Muriel Thoby-Brisson, Jean-Baptiste Trinh, Jean Champagnat, and Gilles Fortin \\ Laboratoire de Neurobiologie Génétique et Intégrative, Institut Alfred Fessard, Centre National de la Recherche Scientifique, 91198 Gif sur Yvette, France
}

To obtain insights into the emergence of rhythmogenic circuits supporting respiration, we monitored spontaneous activities in isolated brainstem and medullary transverse slice preparations of mouse embryos, combining electrophysiological and calcium imaging techniques. At embryonic day 15 (E15), in a restricted region ventral to the nucleus ambiguus, we observed the onset of a sustained highfrequency (HF) respiratory-like activity in addition to a preexisting low-frequency activity having a distinct initiation site, spatial extension, and susceptibility to gap junction blockers. At the time of its onset, the HF generator starts to express the neurokinin 1 receptor, is connected bilaterally, requires active AMPA/kainate glutamatergic synapses, and is modulated by substance $\mathrm{P}$ and the $\mu$-opioid agonist D-Ala ${ }^{2}-\mathrm{N}$-Me-Phe ${ }^{4}$-Glycol ${ }^{5}$-enkephalin. We conclude that a rhythm generator sharing the properties of the neonatal pre-Bötzinger complex becomes active during E15 in mice.

Key words: mouse hindbrain; embryo; rhythm; respiration; calcium imaging; pre-Bötzinger complex

\section{Introduction}

Although a functional respiratory network is necessary for survival at birth, respiratory-like movements are detectable before birth in rats (Kobayashi et al., 2001), mice (Viemari et al., 2003), lambs (Cooke and Berger, 1996), and humans (DeVries et al., 1982; Blanco, 1994; Cosmi et al., 2003). Thus, the respiratory neural network is active at prenatal stages, shortly after the onset of fetal movements. In the mouse, respiratory-like activity has been proposed to start during the last third of the gestation period, at around embryonic day 15 (E15) (Abadie et al., 2000; Viemari et al., 2003), but little is known about the organization of rhythm-generating circuits at this stage. In early development of the vertebrate brain, large neuronal networks are responsible for the generation of immature low-frequency (LF) activities (in minutes $^{-1}$ ) (O'Donovan and Landmesser, 1987; Fortin et al., 1994; Milner and Landmesser, 1999; Abadie et al., 2000; Gust et al., 2003; Ren and Greer, 2003; Yvert et al., 2004). Later in development, central networks generating high-frequency (HF) activities (in seconds ${ }^{-1}$ ) become both regionally restricted in defined anatomical territories and dedicated to the generation of specific motor activities (Kiehn and Kullander, 2004). It is so far poorly understood how these mature networks emerge. In particular,

Received Feb. 10, 2005; revised March 15, 2005; accepted March 21, 2005.

This work was supported by the Centre National de la Recherche Scientifique, by European Grant "Brainstem Genetics" QLG2/CT/2001-01467, and by Action Concertée Incitative from the Ministeré Deléguéá la Recherche Grant BDP0223.

Correspondence should be addressed to Dr. Gilles Fortin, Laboratoire de Neurobiologie Génétique et Intégrative, Institut Alfred Fessard, Centre National de la Recherche Scientifique, 1 avenue de la Terrasse, 91198 Gif sur Yvette, France. E-mail: gilles.fortin@iaf.cnrs-gif.fr.

D0I:10.1523/JNEUROSCI.0551-05.2005

Copyright $\odot 2005$ Society for Neuroscience $\quad$ 0270-6474/05/254307-12\$15.00/0 the links between the establishment of the respiratory rhythm generator and the preexisting immature network active at low frequency are unknown (Abadie et al., 2000; Gust et al., 2003). We have addressed this issue by examining the emergence of neural networks involved in respiratory rhythm generation in the mouse embryo.

The respiratory rhythm is generated by neuronal groups located in restricted areas in the reticular formation of the ventrolateral medulla. One of these neuronal groups, localized bilaterally in the pre-Bötzinger complex (PBC), a region immunoreactive for the neurokinin receptor neurokinin 1 (NK1) (Gray et al., 1999; Wang et al., 2001; Pagliardini et al., 2003; Stornetta et al., 2003), is thought to contain all of the necessary elements for respiratory rhythm generation (Smith et al., 1991; Koshiya and Guyenet, 1996; Ramirez et al., 1998; Lieske et al., 2000). This group is readily identifiable and amenable to analysis in in vitro preparations. The respiratory neural network in the PBC region contains rhythmic neurons connected by glutamatergic synapses, some of them exhibiting pacemaker properties (Johnson et al., 1994; Koshiya and Smith, 1999; Thoby-Brisson et al., 2000; Thoby-Brisson and Ramirez, 2001; Pena et al., 2004). The destruction of neurons expressing the NK1 receptor (NK1R) leading to an ataxic respiration (Gray et al., 2001) supports the view that the PBC plays a primary role in respiratory rhythmogenesis. A second group of neurons located ventral to the facial nucleus, named the parafacial respiratory group (pFRG), which is synaptically connected to the PBC network, has been identified recently as also playing an important role in respiratory rhythm generation (Onimaru and Homma, 2003; Coutinho et al., 2004; Onimaru et al., 2004).

In the present study, using immunohistochemical, electrophysiological, and calcium imaging techniques, we provide evidence showing that the respiratory-like HF rhythm generator in the $\mathrm{PBC}$ region is anatomically and functionally defined in the 
mouse embryo at E15. It is distinct from, but transiently coexists with, the primordial network producing LF activity.

\section{Materials and Methods}

All experiments were performed in accordance with ethical guidelines defined by the French Agricultural Ministry and the European Union Council Directive for the Care and Use of Laboratory Animals (number 2889).

In vitro preparations. Pregnant OF1 mice (Janvier, Le Genest Saint Isle, France) were killed by cervical dislocation on E13-E18. The morning after the overnight matings, when the vaginal plug was detected, was considered E0. Embryos were excised from the uterus and kept until the electrophysiological recording session in oxygenated artificial CSF (a-CSF) at room temperature. The a-CSF composition was as follows (in mM): $128 \mathrm{NaCl}, 8 \mathrm{KCl}, 1.5 \mathrm{CaCl}_{2}, 1$ $\mathrm{MgSO}_{4}, 24 \mathrm{NaHCO}, 0.5 \mathrm{Na}_{2} \mathrm{HPO}_{4}, 30$ glucose, $\mathrm{pH}$ 7.4. Brainstem and slice preparations were dissected in this solution at $4^{\circ} \mathrm{C}$. Brainstems were isolated by a rostral section performed at the junction between the mesencephalon and the rhombencephalon, and a caudal section was performed between the two first cervical roots. Cranial nerves were carefully dissected for nerve recordings (see below). The preparations were then transferred to a recording chamber and continuously superfused with oxygenated a-CSF at $30^{\circ} \mathrm{C}$.

Transverse medullary slice preparations were obtained by serially sectioning brainstems in the transverse plane from rostral to caudal using a vibratome. Based on the procedure described for isolating the HF respiratory generator in newborn animals (Smith et al., 1991; Ramirez et al., 1996), we isolated a $450-\mu$ m-thick slice, the anterior limit of which was set 200-300 $\mu \mathrm{m}$ caudal to the posterior limit of the facial nucleus and that contained the caudal part of the reticular formation and the hypoglossal nucleus. Thus, the anterior side of the slice is cut through the putative pre-Bötzinger complex with rhythmogenic cells being close to the surface, allowing their calcium variations and electrophysiological recordings. The preparation positioned with its rostral surface up was then placed in a recording chamber maintained at $30^{\circ} \mathrm{C}$ and continuously perfused with oxygenated a-CSF. As a control, we also isolated a $450-\mu \mathrm{m}-$ thick slice obtained at a more rostral level, which contained the facial motor nucleus.

Recordings. Recordings of cranial nerves in isolated brainstems and local population activity in slices were performed using glass micropipettes (tip diameter, $150 \mu \mathrm{m}$ ) as suction electrodes positioned on the proximal end of the hypoglossal nerve root or on the surface of the slice. The micropipettes filled with a-CSF were connected through silver wires to a high-gain AC amplifier (7P511; Grass Instruments, Quincy, MA), filtered (bandwidth, $3 \mathrm{~Hz}$ to $3 \mathrm{kHz}$ ), integrated using an electronic filter (time constant, 100 ms; Neurolog system; Digitimer, Hertfordshire, UK), recorded on a computer via a digitizing interface (Digidata 1322A; Axon Instruments, Foster City, CA), and analyzed with pClamp9 software (Axon Instruments). Spontaneous activity was considered to show a low or high frequency pattern when the frequency of spontaneous burst discharges was below three bursts per minute or above three bursts per minute, respectively. An LF-HF pattern was identified when two types of activity generated at distinct frequencies were observed on the same preparation in control conditions. In LF-HF preparations, HF frequency was measured between LF bursts.

Whole-cell patch-clamp recordings were performed under visual control using differential interference contrast and infrared video microscopy, an Axoclamp2A amplifier (Axon Instruments), a digitizing inter-

\section{C- Distribution}

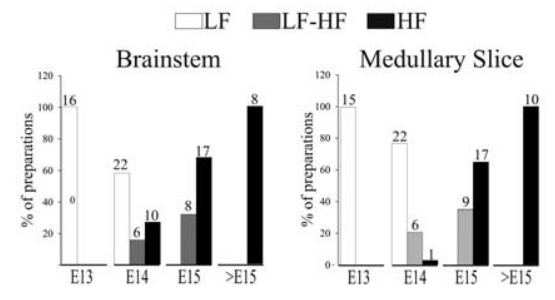

D- Facial slice

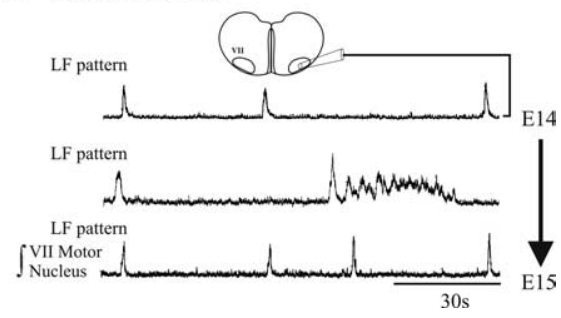

inct discharge Trigeminal nerve exit point; $7 n$, facial nerve exit point; $9 n$, glossopharyngeal nerve exit point; $10 n$, vagus nerve exit point; $12 n$, facial motor nucleus.

face (Digidata 1322A; Axon Instruments), and the software program pClamp9 (Axon Instruments). Neurons recorded were located ventral to the nucleus ambiguus (NA), close to the suction electrode recording population activity. Patch electrodes (resistance, 4-6 M $\Omega$ ) were pulled from borosilicate glass tubes (GC 150TF; Clark Electromedical Instruments, Pangbourn, UK) and filled with a solution containing the following (in mM): $123 \mathrm{~K}$-gluconic acid, $21 \mathrm{KCl}, 0.5 \mathrm{EGTA}, 3 \mathrm{MgCl}_{2}$, $10 \mathrm{HEPES}$, $\mathrm{pH} 7.2$, supplemented with $1 \mathrm{mg} / \mathrm{ml}$ biocytine (Molecular Probes, Eugene, OR) and later revealed with Extravidine-FITC (1:400; Sigma, St. Louis, MO). $I-V$ curves were obtained by measuring the amplitude of the current evoked by $0.5 \mathrm{~s}$ duration voltage steps from -100 to $+30 \mathrm{mV}$. Current amplitude was measured at steady state ( $400 \mathrm{~ms}$ after the beginning of the voltage step). The $I_{\mathrm{h}}$ current was isolated by applying $2 \mathrm{~s}$ duration $10 \mathrm{mV}$ incrementing hyperpolarizing voltage steps from a holding potential of $-50 \mathrm{mV}$. The net $I_{\mathrm{h}}$ current was measured by subtracting for each voltage step (from -50 to $-120 \mathrm{mV}$ ) the current measured at the beginning of the step to the one measured at the end of the step.

Drugs were obtained from Sigma, dissolved in a-CSF, and bath applied for $10-15 \mathrm{~min}$ at the final concentration of $0.1 \mu \mathrm{M}$ for substance P (SP),

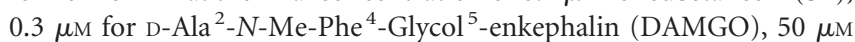
for carbenoxolone (CBX), $100 \mu \mathrm{M}$ for octanol, $100 \mu \mathrm{M}$ for heptanol, and $20 \mu \mathrm{M}$ for 6-cyano-7-nitroquinoxaline-2,3-dione (CNQX). A pressure pulse ( $50 \mathrm{~ms}, 0.7$ bar) was applied to a patch pipette, filled with GABA (1 $\mathrm{mM}$ ) or NMDA (1 $\mathrm{mm}$ ) diluted in a-CSF, which was positioned right below the surface of the slice in the putative rhythm-generating ventrolateral area of the slice to test the presence of evoked contralateral excitatory responses.

Values are given as means \pm SEM, and statistical significance was tested using paired difference Student's $t$ test. Values were assumed to be significantly different at $p<0.05$.

Calcium imaging. Slices were incubated for $45 \mathrm{~min}$ in oxygenated a-CSF containing the cell-permeant calcium indicator dye Calcium Green-1 AM (10 $\mu \mathrm{M}$; Molecular Probes). After a 30 min recovery period 


\section{A- Control, LF-HF pattern}

E15 Transverse slice

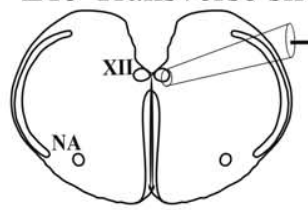

$\int$ XII Motor $\int_{\text {Nucleus }}$

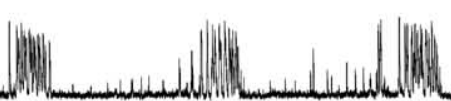

\section{B- CBX $50 \mu \mathrm{M}$}

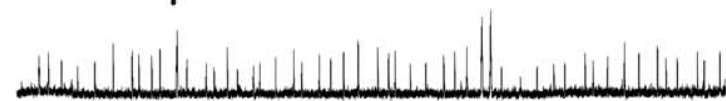

C- Wash out

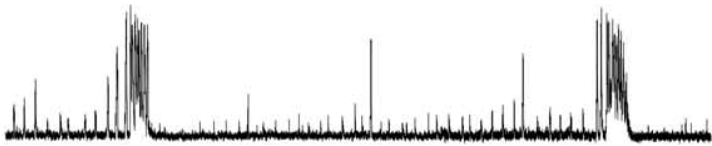

D- CNQX $20 \mu \mathrm{M}$

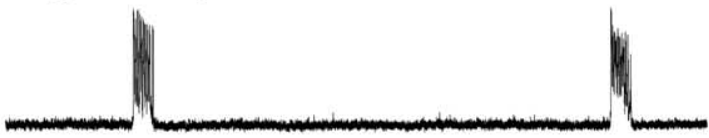

\section{E- Wash out}

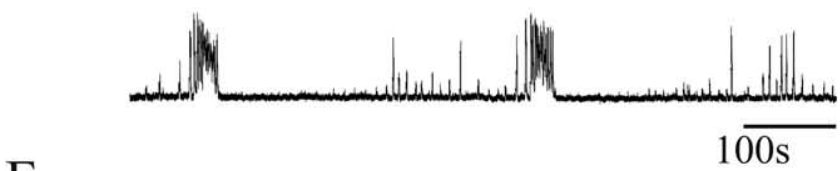

F-

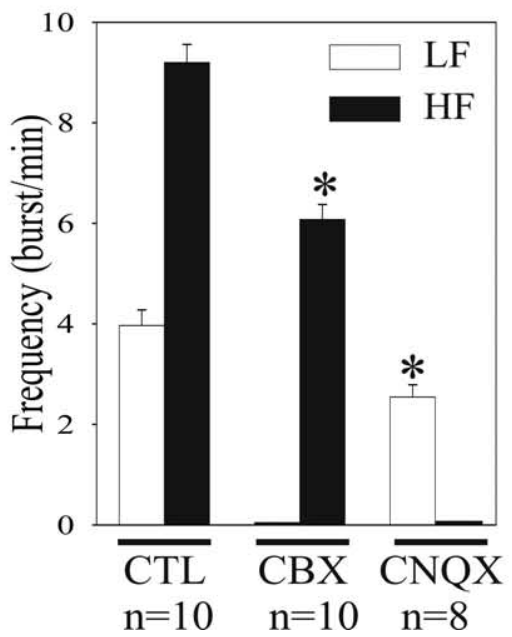

Figure 2. LF and HF activities rely on distinct synaptic mechanisms. Integrated population activity of the hypoglossal motor nucleus (XII) in E15 transverse slice (scheme on top) exhibiting an LF-HF pattern recorded in control conditions $(\boldsymbol{A})$, after blockade of electrical coupling with 15-min-long application of $50 \mu \mathrm{M} C B X(B)$, or blockade of glutamatergic AMPA/kainate receptors with $20 \mu \mathrm{M}$ CNQX applied during $15 \mathrm{~min}(\boldsymbol{D})$ and after washout of exogenously applied drugs $(\boldsymbol{C}, \boldsymbol{E})$. CBX selectively blocked LF activity, whereas CNQX selectively suppressed HF activity. $\boldsymbol{F}$, Graph representing the mean frequency for LF (white bars) and HF (black bars) bursts in the different experimental conditions (cited below the graph). Both the HF activity spared by CBX and the LF activity spared by CNQX had a slower frequency $\left({ }^{*} p<0.05\right)$. CTL, Control. Error bars represent SEM.

\section{A- E15, HF pattern}
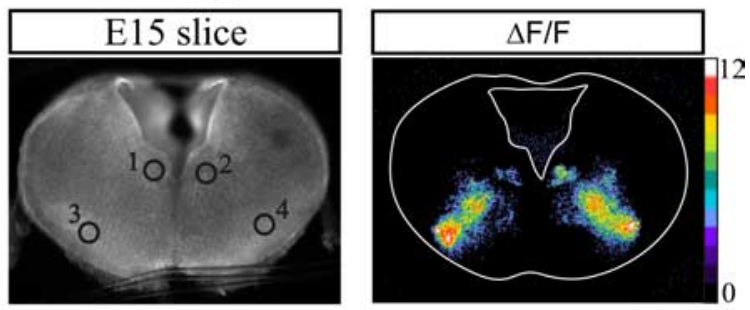

Area 1
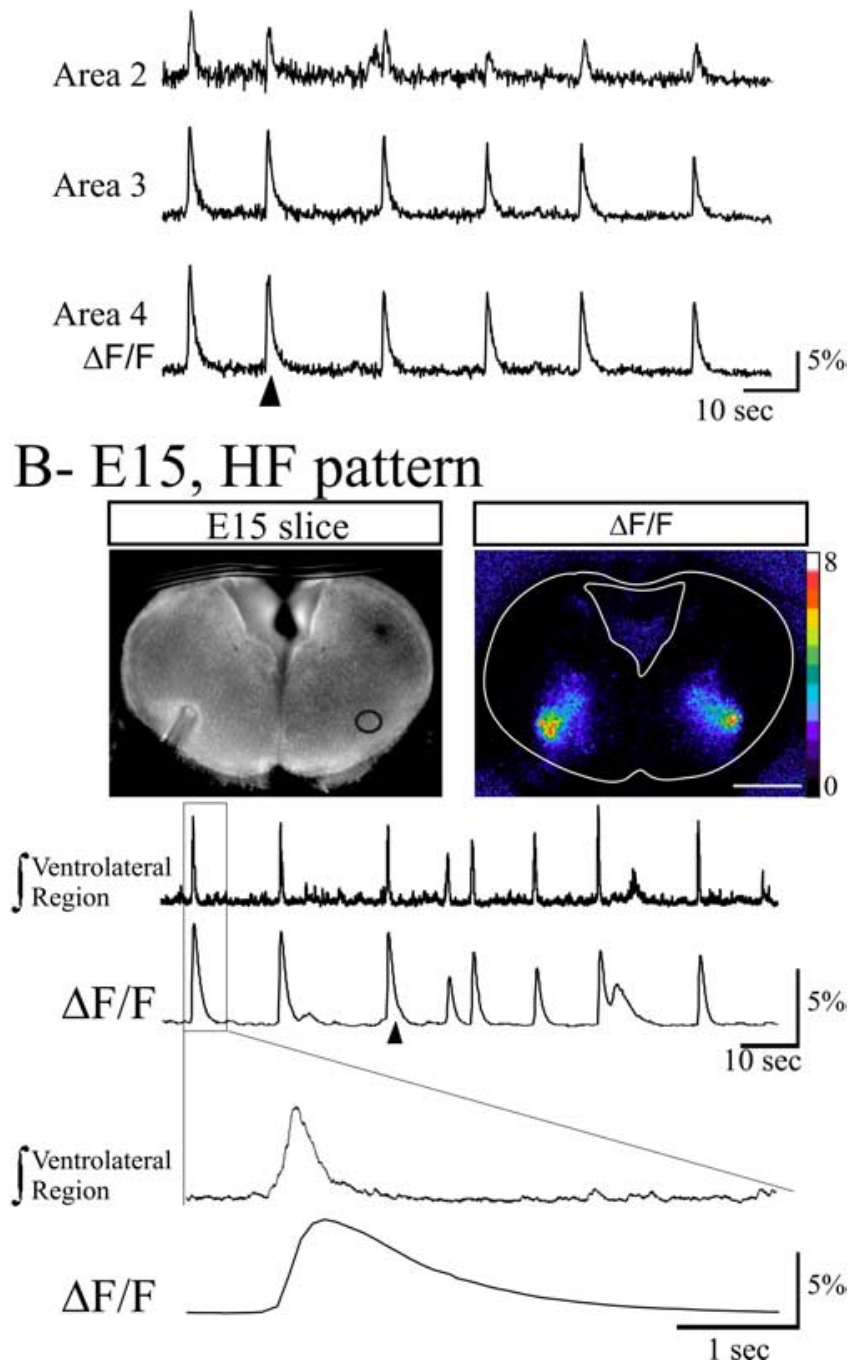

Figure 3. Calcium imaging of HF activity in medullary slices loaded with Calcium Green-1 AM. A, Photomicrograph of the transverse medullary slice obtained from an E15 embryo loaded with the calcium indicator Calcium Green-1 AM in fluorescence (left) showing spontaneous calcium transients illustrated as relative changes in fluorescence (right). Spontaneous calcium transients were observed and measured (4 traces in the bottom) in four active areas (marked circles numbered 1-4 on the left image) corresponding to the hypoglossal nuclei $(1,2)$ and ventrolateral areas (3,4). $\boldsymbol{B}$, Combined calcium imaging and recording of the ventrolateral area population activity. Fluorescence image (left) showing the position of the recording electrode in the ventrolateral area from which the integrated activity (top trace) was recorded and the area (circle) used for measurement of $\Delta F / F$ (right and bottom trace). Note the correlation between electrical bursts of activity and calcium transients. The event outlined on top traces with the rectangle is illustrated at an extended time scale on the two bottom traces to indicate the different time course of the electrical and calcium signals. Calibration bars in $A$ and $B$ indicate the $\Delta F / F$ percentage change. The $\Delta F / F$ images were taken at the time indicated by the arrowheads below the $\Delta F / F$ traces. 
in the recording chamber to wash out the dye, a standard epifluorescent illumination system on an E-600-FN upright microscope (Nikon, Tokyo, Japan) equipped with a fluorescein filter block was used to excite the dye and capture the emitted light. Fluorescence images were captured with a cooled CCD camera (Coolsnap HQ; Photometrics, Tucson, AZ) using an exposure time of $100 \mathrm{~ms}$ in overlapping mode (simultaneous exposure and readout) during periods of $30-120 \mathrm{~s}$ and analyzed using MetaMorph software (Universal Imaging Corporation, West Chester, PA). The average of intensity in region of interest was calculated for each frame, and changes in fluorescence were normalized to their initial value by expression as the ratio of changes in fluorescence to initial fluorescence $(\Delta F / F)$.

Immunostaining. Brainstem preparations were fixed for 3-4 h in 4\% paraformaldehyde, cryoprotected in $30 \%$ sucrose-PBS overnight and then cryosectioned at $30 \mu \mathrm{m}$. For Islet1,2 and NK1 double immunostaining, sections were incubated for $30 \mathrm{~min}$ in $1 \% \mathrm{BSA}$ and $0.5 \%$ Triton X-100, followed by affinity-purified guinea pig anti-Islet1,2 (1:1500; gift from Dr. J. Ericson, Karolinska Institute, Stockholm, Sweden) and rabbit anti-NK1 (1:5000; Sigma) overnight at room temperature. After rinsing in PBS, sections were exposed to the following secondary antibodies for $3 \mathrm{~h}$ : FITC-conjugated goat anti-guinea pig IgG (1:400; Promega, Madison, WI) and Alexa Fluor 594-conjugated goat anti-rabbit IgG (1:400; Molecular Probes). After rinsing with PBS, sections were coverslipped and mounted in PBS-glycerol (50:50). Control experiments in which the primary antibodies were replaced by normal serum exhibited no labeling.

\section{Results}

Maturation of motoneuronal activities in isolated brainstem and transverse slice preparations of mouse embryos Spontaneous activity was recorded in vitro from hypoglossal motoneuron rootlets and somata on respectively isolated brainstem and transverse medullary slice preparations from E13-E18 embryos. In both preparations, we observed three distinct patterns of activity developing during this time window (Fig. $1 A, B$ ).

First, preparations generated an LF pattern (brainstems, $1.31 \pm 0.05 \mathrm{burst} / \mathrm{min}, n=7$; slices, $2.85 \pm 0.16 \mathrm{burst} / \mathrm{min}, n=$ 9) (Fig. $1 A, B$, top traces). This LF pattern was observed in $100 \%$ of E13 preparations (brainstems, 16 of 16 cases; slices, 15 of 15 cases), in 58 and 76\%, respectively, of brainstem (22 of 38 cases) and slice (22 of 29 cases) preparations at E14 and in 0\% of older (E15-E18) preparations (brainstems, 0 of 33 cases; slices, 0 of 36 cases) (Fig. 1C).

Second, we observed a mixed pattern, composed of bursts generated at low frequency (brainstem, $0.83 \pm 0.03 \mathrm{burst} / \mathrm{min}$, $n=8$; slices, $1.89 \pm 0.17 \mathrm{burst} / \mathrm{min}, n=5$ ), coexisting with burst discharges generated at $\mathrm{HF}$ (brainstem, $13.7 \pm 0.3 \mathrm{burst} / \mathrm{min}, n=$ 8; slice, $7.64 \pm 0.4$ burst $/ \mathrm{min}, n=5$ ) in between LF bursts to form an LF-HF pattern (Fig. $1 A, B$, middle traces). The LF-HF pattern was absent at E13 and in preparations older than E15 but was identified in $16 \%$ of brainstem ( 6 of 38 cases) and $21 \%$ of slice ( 6

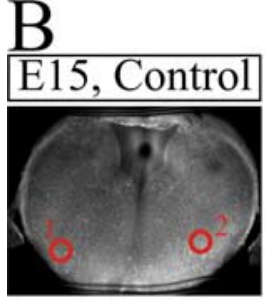

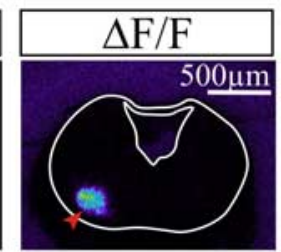

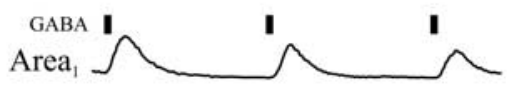

Area $_{2} \longrightarrow \Delta \mathrm{F} / \mathrm{F}$
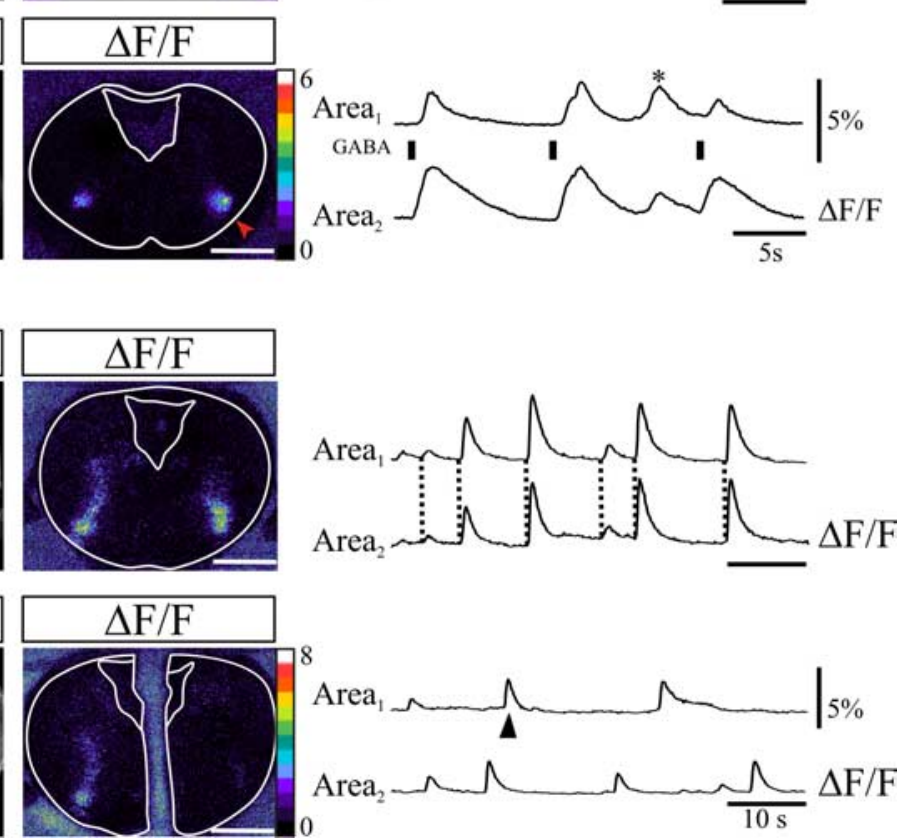

Figure 4. The two ventrolateral HF generators are synchronized through commissural connections established at E15. $\boldsymbol{A}$, Top, The left image shows an E14 transverse slice in fluorescence and ventrolateral areas (red circles 1,2) where changes in fluorescence in ventrolateral areas (red circles 1, 2) on control (top) and after section along the midline (red double-headed arrow). Note that the bilateral synchrony of calcium transients (dotted lines on top set of traces) is lost after the section, whereas the ability to generate HF bursts is preserved in each hemislice. The $\Delta F / F$ image was taken at the time indicated by the arrowhead under the area 1 trace. Scale bars, $500 \mu \mathrm{m}$.

of 29 cases) preparations at E14 and in 32\% of brainstems ( 8 of 25 cases) and $35 \%$ of slices ( 9 of 26 cases) at E15 (Fig. 1C).

Third, we observed a sustained HF pattern (Fig. $1 A, B$, bottom traces) composed of burst discharges generated at a mean frequency of $10.7 \pm 0.5$ and $8.1 \pm 0.2 \mathrm{burst} / \mathrm{min}$ in seven brainstem and nine slice preparations, respectively. This HF pattern was present in $26 \%$ of the brainstems and $3 \%$ of the slices recorded at E14, in $68 \%$ of the brainstems (17 of 25 cases) and $65 \%$ of the slices (17 of 26 cases) at E15, and in 100\% (eight brainstems, 10 slices) of older (E16-E18) preparations (Fig. 1C). Hence, the establishment of the sustained HF rhythmic activity is primarily operated at E15 and is complete by E16.

We also examined the activities recorded in nonoverlapping transverse slices performed at the more rostral anteroposterior (AP) level of the facial nucleus. In these slices, the activity of facial motoneurons at E14 (one of one slice) and E15 (three of three slices) showed a LF pattern but failed to show LF-HF or HF patterns (Fig. 1D). This LF activity was composed of burst discharges generated at a mean frequency of $2.7 \pm 0.4 \mathrm{burst} / \mathrm{min}$ $(n=4)$. Thus, the ability to generate the LF pattern may owe to 

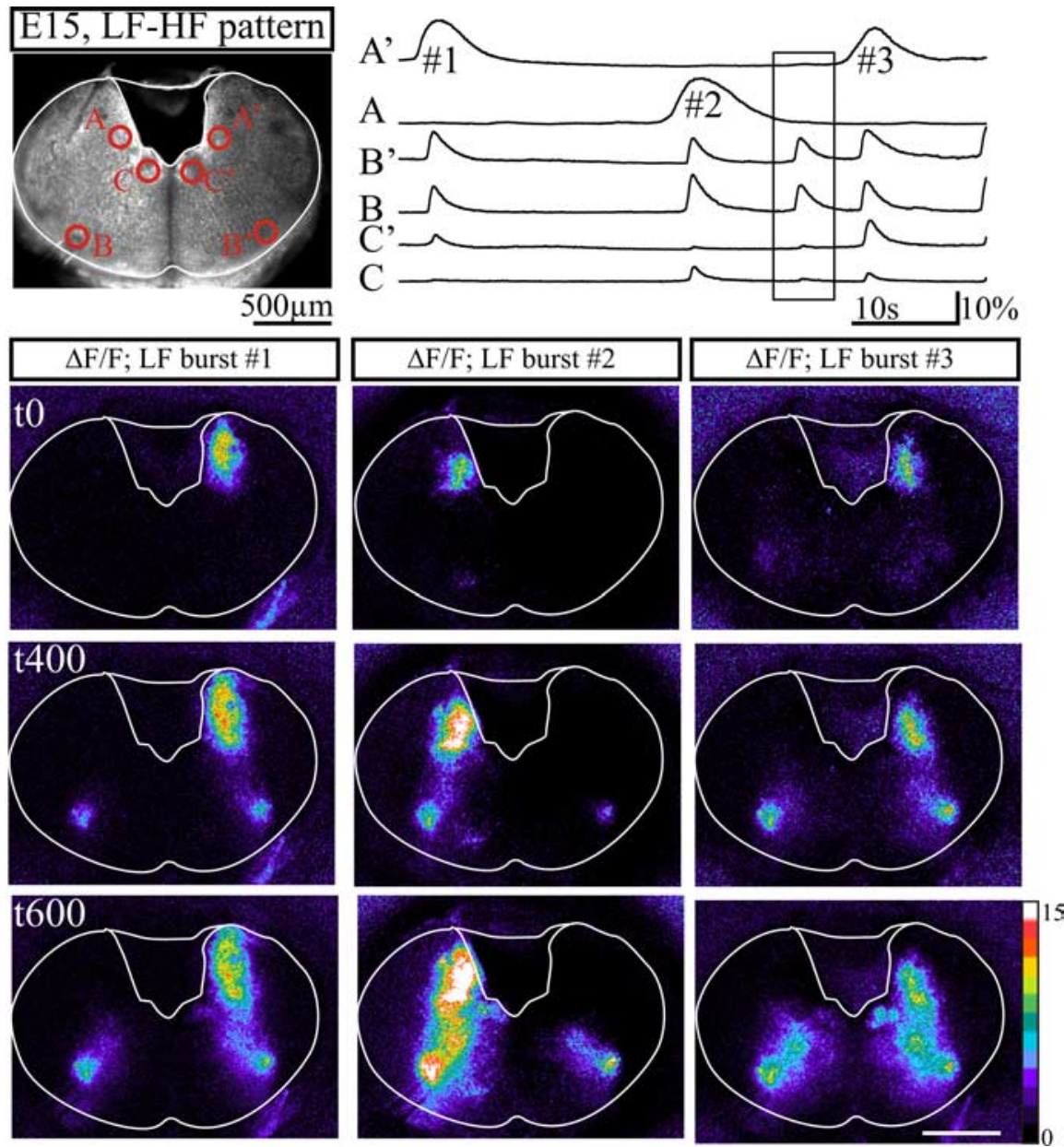

Figure 5. Sequential activation of the dorsal and the ventral active regions. Top, Image of a transverse slice exhibiting an LF-HF pattern obtained from an embryo at E15 in fluorescence. Spontaneous calcium changes were measured ( 6 traces on the right) in areas marked by red circles. Areas $\boldsymbol{A}$ and $\boldsymbol{A}^{\prime}$ correspond to initiation sites of LF activity. $\boldsymbol{B}$ and $\boldsymbol{B}^{\prime}$ correspond to the ventrolateral initiation sites of $\mathrm{HF}$ activity. $\boldsymbol{C}$ and $\boldsymbol{C}^{\prime}$ correspond to the hypoglossal nuclei. Bottom, Relative calcium changes $(\Delta F / F)$ observed during three successive LF bursts numbered 1, 2, 3 on $\boldsymbol{A}^{\prime}$ and $\boldsymbol{A}$ top traces and heading tags above columns, illustrating from top to bottom calcium activities sampled at the time of initiation of the LF burst (t0), $400 \mathrm{~ms}$ (t400) and $600 \mathrm{~ms}$ (t600) later. Note that LF activity initiating in the dorsomedial area of the slice extends ventrally and activates ventrolateral areas (t400; middle row), in turn activating dorsomedial targets including the region of the hypoglossal nuclei (t600; bottom row). The initiation site of LF events alternated in time from one side to the other and with ongoing spontaneous calcium activity generated in the ventrolateral area shown in the rectangular box on traces. Scale bars, $500 \mu \mathrm{m}$.

neural properties widely distributed in the embryonic brainstem, whereas HF patterns could rely on AP-restricted active circuits preserved in transverse medullary slices caudal to the facial nucleus.

Different synaptic mechanisms underlie LF and HF activities To investigate synaptic mechanisms supporting LF and HF patterns of activity, we used a pharmacological approach on E15 medullary slices exhibiting the LF-HF pattern (Fig. 2A). Bath application of the gap junction blockers CBX (50 $\mu \mathrm{M} ; n=10)$, octanol (100 $\mu \mathrm{M} ; n=4)$, and heptanol (100 $\mu \mathrm{M} ; n=3)$ suppressed LF events ( $n=17$ of 17 ) (Fig. $2 B$ ), whereas the HF activity persisted at a reduced rate $(6.0 \pm 0.3 \mathrm{burst} / \mathrm{min}$ in CBX vs $9.1 \pm 0.3 \mathrm{burst} / \mathrm{min}$ in control; $n=10$ ) (Fig. $2 \mathrm{~F}$ ). In contrast, blockade of AMPA/kainate receptors with $20 \mu \mathrm{M}$ CNQX abolished the HF rhythm but spared the LF activity $(n=8$ of 8 ) (Fig. 2, compare $C, D)$. Under CNQX, the frequency of the LF activity was reduced by $\sim 35 \%$ (from $3.9 \pm 0.3 \mathrm{burst} / \mathrm{min}$ in control to $2.5 \pm 0.2$ burst $/ \mathrm{min}$ under CNQX) (Fig. 2 F). Similar results were obtained for preparations exhibiting a single pattern discharge (either LF or HF). Blocking NMDA receptor-mediated transmission with APV $(50 \mu \mathrm{M} ; n=6)$, $\mathrm{GABA}_{\mathrm{A}}$ receptor-mediated transmission with bicuculline ( $20 \mu \mathrm{M} ; n=6)$, glycinergic transmission with strychnine $(5 \mu \mathrm{M}$; $n=5$ ), or cholinergic transmission with dihydro- $\beta$-erythroidine hydrobromide ( 5 $\mu \mathrm{M} ; n=2$ ) was ineffective in altering either activity (data not shown). The selective susceptibility to electrical and glutamatergic synaptic communication indicates that LF and HF activities are mediated by primarily independent intercellular communication mechanisms. It is unclear at this point whether the pharmacological suppression of LF and HF activities altered the propagation of activities to the recording sites or the activity generation mechanisms.

\section{Spatial organization of HF circuits}

The spatial organization of neuronal circuits supporting the HF pattern of activity of the hypoglossal motoneurons was examined in E15 slices loaded with the calcium indicator Calcium Green-1 AM. Using continuous calcium imaging, we detected spontaneous calcium activity changes in the hypoglossal area but also changes of fluorescence in two ventrolateral areas of the slice (Fig. $3 A$ ). Calcium changes in these regions had a time to peak of $461 \pm 67 \mathrm{~ms}(n=4)$ and a time constant for decay of $1157 \pm 191 \mathrm{~ms}(n=4)$ and occurred at a rate similar to that of the HF activity identified by electrophysiological recordings. We verified that calcium changes indeed reflected electrical activity by simultaneously recording electrophysiological and calcium signals (Fig. 3B).

Systematic analysis of the site of initiation of this HF activity revealed that the calcium activity variations first recruited neuronal populations within the ventrolateral areas of the slice and progressed dorsally toward the hypoglossal region. The initiation site always appeared as two ovoid territories with its largest extension of $\sim 0.2$ $\mathrm{mm}(190 \pm 42 \mu \mathrm{m})$ located at a minimal distance of $\sim 0.15 \mathrm{~mm}$ $(155 \pm 36 \mu \mathrm{m})$ from the pial surface of the slice with a medial limit at $\sim 0.6 \mathrm{~mm}(614 \pm 42 \mu \mathrm{m})$ from the midline. This location was highly consistent among recorded slices and contrasted with the variable extension of the calcium activity spread toward the hypoglossal nuclei. In fact, calcium changes at the level of the hypoglossal motor nuclei were sometimes barely detectable, although paired electrophysiological recordings of the hypoglossal motor nucleus revealed ongoing HF activity (data not shown). When detectable, the hypoglossal HF signal was delayed by $\sim 200$ $\mathrm{ms}$ with respect to the ventrolateral site. This sequential activation of the ventrolateral area and the hypoglossal motor nucleus was also observed for the HF calcium events contributing to the LF-HF pattern. 


\section{Commissural connections are} established at E15

To identify possible commissural connections between the ventrolateral areas before onset of HF activity, we performed pressure ejections of NMDA (1 $\mathrm{mm})$ or GABA (1 mM) onto one ventrolateral area at E14 on preparations exhibiting no HF activity (Fig. 4). We found that calcium responses could be evoked by either compound in the vicinity of the application site but at this stage failed to trigger any detectable calcium variation in the corresponding contralateral position of the slice (Fig. $4 A$, top). In contrast, the same experiment performed on E15 slices induced bilateral calcium variations (Fig. $4 A$, bottom). A section along the midline of E15 slices (Fig. $4 B$ ) rendered asynchronous the HF rhythmic activities in the ventrolateral area of each isolated hemislices. These experiments demonstrate a depolarizing action of GABA at these stages and confirm that the initiation of the HF activity is bilateral. Furthermore, we failed to ever observe unilateral HF activity in the ventrolateral area, suggesting that commissural connections are required for emergence of the $\mathrm{HF}$ pattern but are dispensable for the maintenance of this pattern thereafter.

\section{LF activity is not initiated in the ventrolateral area}

On preparations exhibiting either LF pattern or LF-HF pattern, LF bursts arose unilaterally from a dorsomedial area flanking the fourth ventricle (Fig. 5). LF calcium changes in this region of the slice exhibited time to peak responses (985 \pm $71 \mathrm{~ms} ; n=4$ ) about twice as long as HF bursts and a comparable decay constant of $972 \pm 188 \mathrm{~ms}(n=4)$. The LF events were initiated from either the right or the left side of the slice and often alternated in time from one side to the other, as shown on Figure 5. From this dorsomedial domain, the calcium activity extended in a ventral direction and recruited the ventrolateral areas generating the HF activity, which in turn led to activation of the hypoglossal nuclei. Thus, the unilateral initiation site led to bilateral activation of the ventrolateral areas. These experiments indicate that when HF and LF activities coexist, the HF site could be activated by a LF-spreading activity generated in remote sites flanking the lumen of the fourth ventricle.

In keeping with pharmacological experiments illustrated in Figure 2, blockade of gap junctions by carbenoxolone selectively suppressed LF calcium events, whereas the HF calcium activity was maintained, albeit at a reduced rate (Fig. $6 A-C$ ). Conversely, bath application of CNQX eliminated calcium activity in the ventrolateral area, whereas the LF calcium activity was maintained (Fig. 6A,D,E). These experiments demonstrate that these pharmacological challenges targeted LF and HF generation mechanisms.

\section{B- Control}
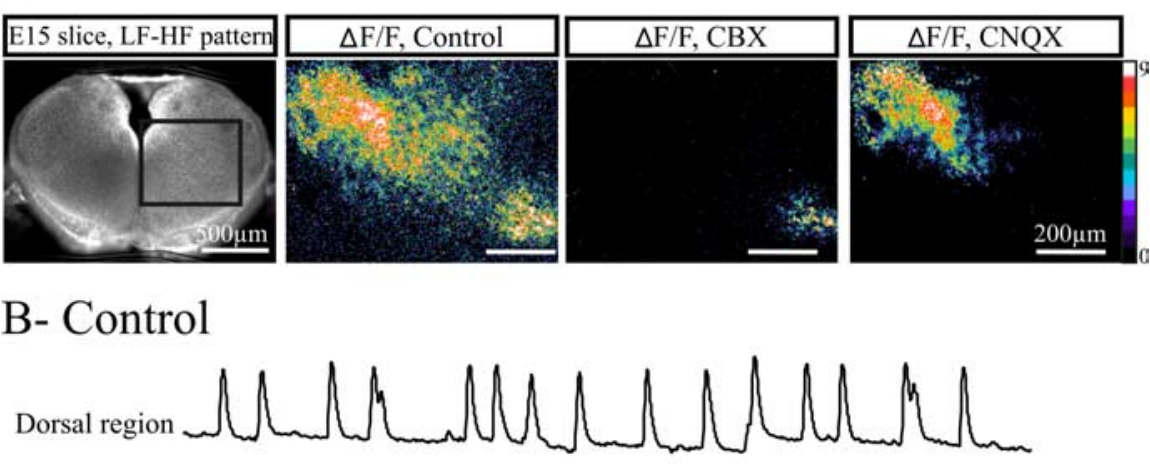

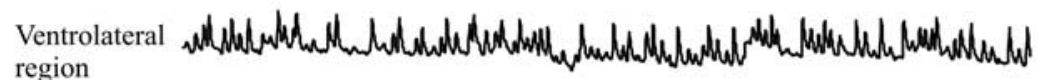

\section{C- CBX $50 \mu \mathrm{M}$}
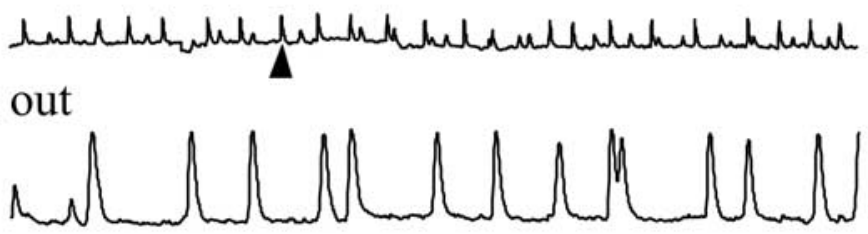

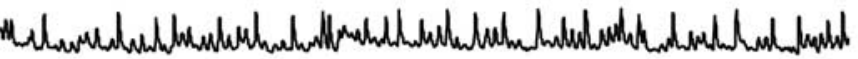

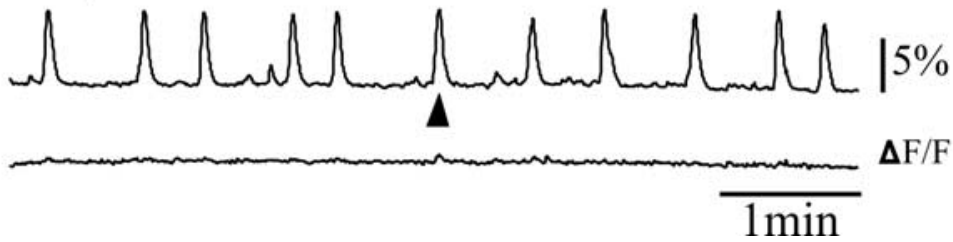

Figure 6. Distinct synaptic mechanisms underlie LF and HF activity generation. $\boldsymbol{A}$, The transverse medullary slice at E15 in direct fluorescence (left) showing the area where calcium variations $(\Delta F / F)$ were measured in control conditions (left), after $10-15$ min application of CBX (middle), and after blockade of AMPA/kainate receptors with CNQX (right; $15 \mathrm{~min}$ ). The $\Delta F / F$ images were

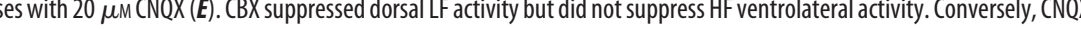
optimal as the sampling of fluorescence changes has been reduced ( $1 / 800 \mathrm{~ms}$ instead of $1 / 100)$ in this particular experiment to minimize bleaching during this long continuous recording. Scale bars: ( $\Delta$ F/F images) $200 \mu \mathrm{m}$.

\section{Neurokinin 1 receptor expression between E13 and E16}

We determined the expression profiles of NK1Rs and Islet1,2, an early marker of motoneurons, in transverse slices obtained during the E13-E16 developmental period (Fig. 7). At E13, NK1R was mainly expressed in the midline, as described in the spinal cord (Heath et al., 1995; Horie et al., 2000), whereas Islet1,2positive cells were confined medially at the level of developing hypoglossal motor nucleus and ventrolaterally in the NA (Fig. 7). Starting on E14, it was possible to identify NK1R + processes located ventral to the NA (Fig. 7, arrowhead at E14). At E15, a strong NK1R labeling developed in this region ventral to the NA (Fig. 7, arrowhead at E15) and persisted at older embryonic stages (Fig. 7, E16). More rostrally, NK1R immunoreactivity was also observed at this stage in a region ventral to the facial nucleus probably corresponding to the parafacial respiratory group and 

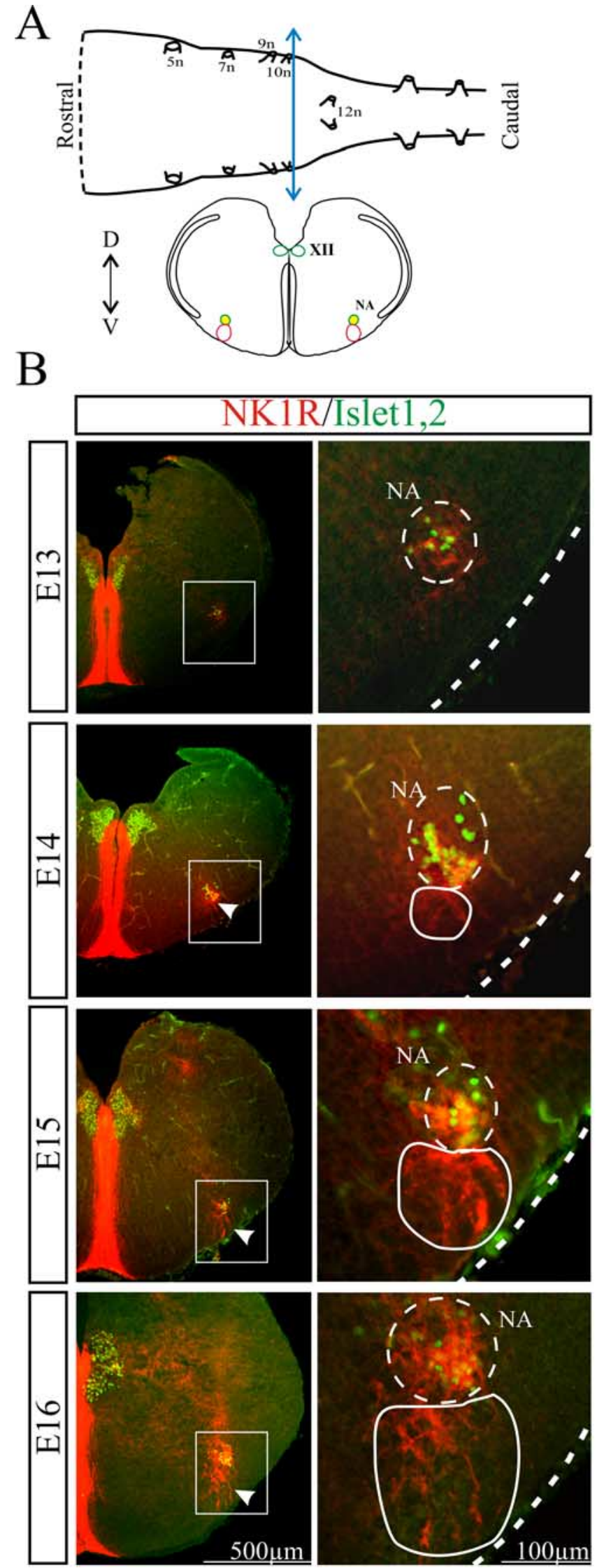

Figure 7. Spatio-temporal distribution of NK1R-positive neurons in transverse brainstem slices at the HF generator axial level. $\boldsymbol{A}$, Schematic representation of an isolated brainstem (top) and a transverse brainstem slice (bottom) obtained after sectioning the brainstem at the level of the blue double-headed arrow. The colored circles represent structures immunoreactive for the retrotrapezoid nucleus (data not shown). The NK1R immunoreactivity observed at E15 in the region ventral to the NA was found in five or six successive $40-\mu \mathrm{m}$-thick slices ( $n=3$ preparations) giving a rostrocaudal extension of $200-250 \mu \mathrm{m}$ for this region positioned $220-250 \mu \mathrm{m}$ caudal to the posterior limit of the facial nucleus.

\section{Membrane properties of neurons within the HF rhythm generator at E15}

On E15 slice preparations, intracellular recordings were performed on neurons within the NK1R-positive ventrolateral area. Twenty-five neurons showed a rhythmic discharge of action potentials in phase with the population activity simultaneously recorded by a nearby suction electrode positioned at the surface of the slice in the ventrolateral area. These neurons had a resting membrane potential of $-50.5 \pm 1.5 \mathrm{mV}$ and an apparent input resistance of $750 \pm 154 \mathrm{M} \Omega(n=14)$. Occasionally, the neuron failed to discharge in phase with population activity (Fig. $8 \mathrm{~A}$, asterisk), thus revealing incoming excitatory (possibly glutamatergic) synaptic inputs from other phase-active neurons of the network. Within the rhythmic neurons examined, we found cells (3 of 28 cells) exhibiting voltage-dependent intrinsic bursting properties. When depolarized by DC current injection, these cells tended to show extra-burst discharges occurring between those recorded from the population activity (Fig. $8 B$ ). $I-V$ curves measured in 14 rhythmic neurons showed an inward rectification at hyperpolarized potentials, suggesting the activation of voltagedependent membrane conductances (Fig. $8 C_{1}$ ). Indeed, we identified the presence of the hyperpolarization activated nonspecific cationic $I_{\mathrm{h}}$ current in nine rhythmic neurons (Fig. 8C ${ }_{2}$ ). Thus, rhythm generation in the ventrolateral area at E15 seems to rely on a network organization consistent with that known to underlie respiratory rhythm generation at birth.

\section{Glutamatergic synchronization within the HF rhythm generator at E15}

The contribution of glutamatergic synaptic transmission in coordinating cellular activities in the ventrolateral area was investigated by monitoring population electrical activity and fluorescence changes occurring in several neurons in the absence and in the presence of CNQX (Fig. 9A). In control, all the cells showing spontaneous changes in fluorescence were found to be synchronously active in phase with the population activity of the HF generator (Fig. 9B). However, these cells clearly differed in their calcium activity between the synchronized events. Forty-one percent ( 63 of 155 cells from four slices) of active cells never showed any detectable calcium transients in between the synchronized events, in contrast with the rest of cells, which showed spontaneous calcium changes in between the synchronized events.

In all cells, application of CNQX suppressed the synchronization of calcium events and the rhythmic population electrical activity (Fig. 9C). As a result, cells previously found inactive in between synchronized bursts stopped emitting, whereas those

$\leftarrow$

NK1R (red), Islet1,2 (green), or both (yellow). B, Distribution of NK1R-positive neurons (red) and Islet1,2-positive motoneurons (green) in transverse brainstem slices at different developmental stages (E13-E16). The right column shows at a higher magnification the area highlighted with the white rectangle in the left column. White arrowheads indicate the immunoreactivity for NK1R starting to appear in the PBC region at E14 (continuous white outline on the right) and present at E15-E16. 5n, Trigeminal nerve exit point; 7n, facial nerve exit point; 9n, glossopharyngeal nerve exit point; 10n, vagus nerve exit point; $12 n$, hypoglossal nerve exit point; XII, hypoglossal nucleus; D, dorsal; V, ventral. 
previously active in between bursts preserved their activity under CNQX. Among this active population (92 of 155 cells), nine cells further retained calcium transients having an amplitude comparable with that of the synchronized calcium transients recorded in control conditions. Interestingly, these calcium changes appeared temporally organized in a somewhat periodic manner, suggesting that these cells may be expressing intrinsic bursting properties (Fig. 9C, highlighted events). Together, these experiments show that cells of the HF generator are synchronized via glutamatergic synapses mediated by AMPA/kainate receptors.

\section{SP and DAMGO modulation of HF activity}

To test the possibility that neuromodulators known to affect the HF respiratory rhythmogenic circuit after birth may already be active at E15, we bath applied SP and the $\mu$-opioid agonist DAMGO on medullary slices while electrophysiologically recording the ventrolateral area population activity (Fig. 10A) or fluorescence changes occurring in several neurons at this level (Fig. 10 B). Bath application of $0.1 \mu \mathrm{M} \mathrm{SP}$ increased the frequency of the rhythmic activity by $85 \%$, from $8.6 \pm 0.3 \mathrm{burst} / \mathrm{min}$ in control conditions to $17.6 \pm 0.7 \mathrm{burst} / \mathrm{min}$ under SP $(n=7)$ (Fig. $10 \mathrm{~A}, B)$. In contrast, DAMGO $(0.3 \mu \mathrm{M})$ decreased significantly the rhythm frequency from $8.4 \pm 1.2$ to $5.56 \pm 1.3 \mathrm{burst} / \mathrm{min}(n=6)$ (Fig. $10 \mathrm{~A})$. These data show that, from the developmental stage when it is first active, the HF generator is sensitive to these neuromodulators.

\section{Discussion}

This study establishes the onset of respiratory-like activity in mouse embryo at E15 and shows that the HF activity coemerges at the same developmental stage as NK1R immunoreactivity in bilateral ventral regions and that commissural connections are established. Moreover, we demonstrate that the HF generator does not derive from the preexisting LF generating network. These data obtained in mouse embryos will be crucial to further determine genetic and trophic control of the establishment of the respiratory network during embryonic development.

\section{LF activity is a primordial activity}

We show that LF activity of hypoglossal rootlets is organized as low-frequency rhythmic bursts and is concomitant in a large number of cells. Generation of this LF activity in the embryonic mouse brainstem does not seem to rely on single anatomical structures or specific circuits, because it was observed in both facial and medullary slices. Spontaneous activity occurring at low rate and invading large territories has been described in various species and a wide variety of developing structures in the CNS such as the spinal cord (O'Donovan and Landmesser, 1987; Chub and O'Donovan, 1998; O'Donovan, 1999; Branchereau et al., 2000; Hanson and Landmesser, 2003; Ren and Greer, 2003; Yvert et al., 2004), the cortex (Garaschuk et al., 2000; Peinado, 2000), the hippocampus (Ben-Ari, 2001), the retina (Galli and Maffei, 1988; Katz and Shatz, 1996), and the brainstem (Fortin et al., 1994; Abadie et al., 2000; Gust et al., 2003). The LF activity ob- served in the present study probably corresponds to an immature activity. Therefore, it likely represents a nonrespiratory activity. This is consistent with previous works obtained in rat (Onimaru and Homma, 2002) and mice (Tsunekawa et al., 2005) combining recordings of $\mathrm{C} 4$ activity with either the diaphragm or the hypoglossal nerve activities and describing at early developmental stages generation of low-frequency discharges not related to respiratory activity.

We provide some insights into the mechanisms controlling LF generation in the brainstem. In several structures, LF activity has been shown to depend either on electrical coupling (Peinado et al., 1993; Kandler and Katz, 1998; Chang et al., 1999; SaintAmant and Drapeau, 2001), on cholinergic neurotransmission (Feller et al., 1996; Milner and Landmesser, 1999; Peinado, 2000; Rossi et al., 2001), or both (Roerig and Feller, 2000; Hanson and Landmesser, 2003). Our data show that in the hindbrain LF activity is not affected by blockade of nicotinic cholinergic transmission, unlike the case in immature spinal cord networks (Hanson and Landmesser, 2003; Ren and Greer, 2003), but is blocked by a number of compounds known to block gap-junction pores as well as "undocked" hemichannels (Bennett et al., 2003; Weissman et al., 2004) (but see Rouach et al., 2003). Gap junctions and hemichannels in the LF network provide electrical and possibly also metabolic signalings necessary for LF activity generation and propagation that may participate in a homeostatic regulation of hindbrain developing networks (Borodinsky et al., 2004; Spitzer et al., 2004).

\section{The HF generator is the respiratory generator}

In the present study, we obtained molecular, synaptic, cellular, and regional level data, all supporting the homology of the E15 HF rhythm generator with the neonatal respiratory neural network in the PBC region. This suggests that the respiratory status of brainstem neural nets may be determined at E15 and maintained thereafter during fetal maturation of neuromodulatory descending respiratory controls (Viemari et al., 2003) and post- 
A

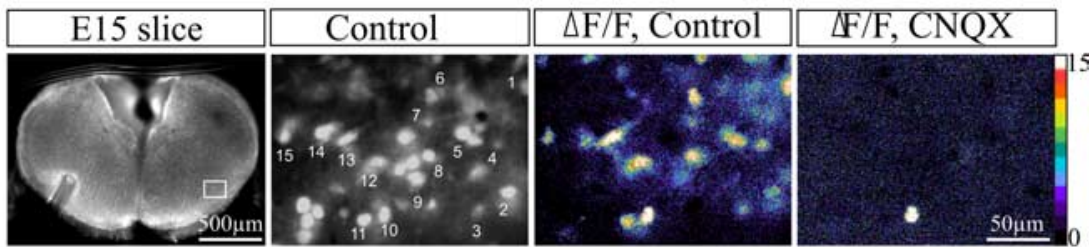

B- Control

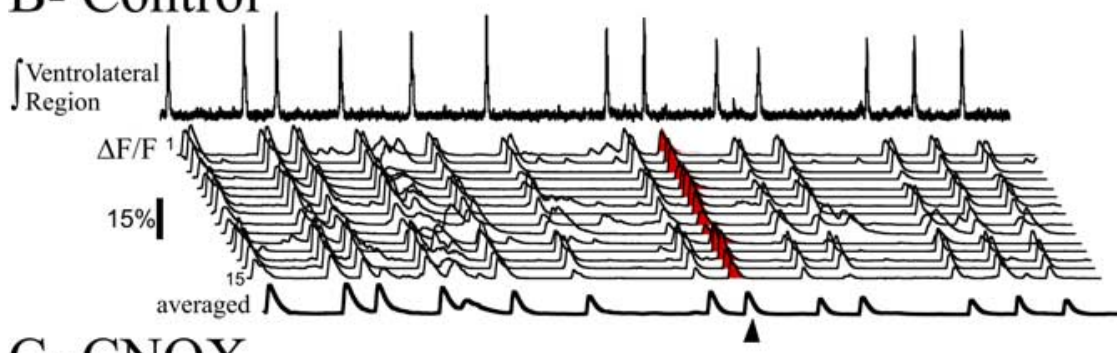

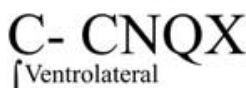

Region

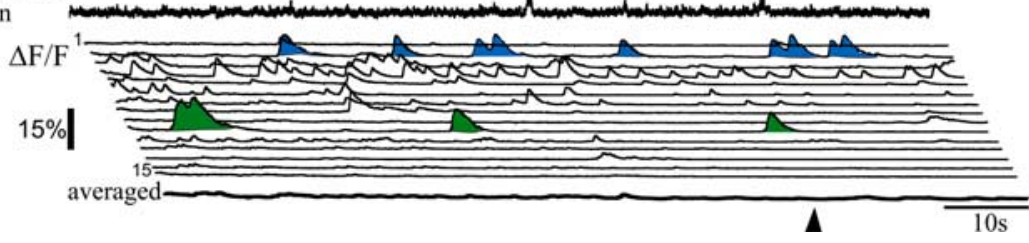

Figure 9. Cells within the HF rhythm generator are synchronized via glutamatergic synapses at E15. $\boldsymbol{A}$, Left, Fluorescence image of an E15 transverse medullary slice at low magnification ( $4 \times$ objective) showing the position of the recording electrode in the left ventrolateral area. The contralateral area delimited by a rectangle shown at higher magnification $(60 \times$ objective; middle left) contains cells numbered 1-15 from which calcium transients were recorded in control conditions $(\Delta F / F, C$ ontrol) and in the presence of CNQX ( $\triangle F / F, C N Q X)$. These images were taken at the time indicated by an arrowhead in $\boldsymbol{B}$ and $\boldsymbol{C}$, respectively. $\boldsymbol{B}$, Paired recordings of the ventrolateral population HF rhythmic activity (top trace) and calcium transients in individual cells numbered 1-15 from top to bottom. Cells show calcium transients synchronized to the bursting electrical activity recorded from the contralateral side. Note the presence of calcium transients in between synchronized events. $\boldsymbol{C}$, In the presence of CNQX, the HF rhythmic population activity was suppressed (top trace), and individual cells either become silent (see cell 15 for example) or preserved spontaneous calcium events that were not synchronized across cells [compare the average trace (thick bottom line) in $\boldsymbol{B}$ and $\boldsymbol{C}$. Calcium events highlighted in green and blue in cell 2 and 10 seem to be generated in a rhythmic manner.

Interestingly, neurons rhythmically active in the embryonic slice preparations express the $I_{\mathrm{h}}$ current, a current known to be involved in the modulation of the respiratory activity in juvenile mice (ThobyBrisson et al., 2000) and in rhythm generation in embryonic hindbrain of chick (Fortin et al., 1999). However, its involvement in the respiratory rhythm generation in mouse embryo remains to be determined. Moreover, this conductance has been recently identified as a target for brain-derived neurotrophic factor (BDNF) (Thoby-Brisson et al., 2003). BDNF reduces $I_{\mathrm{h}}$ amplitude and shifts the $I_{\mathrm{h}}$ activation curve toward more hyperpolarized potential, thus reducing its contribution to voltage-dependent properties of respiratory $\mathrm{PBC}$ neurons. Whether activation properties of the $I_{\mathrm{h}}$ current can already be influenced by functional tyrosine receptor kinase $\mathrm{B}$ receptors at embryonic developmental stage will need to be investigated.

Despite the fact that we found several characteristics of the respiratory neural network already established at E15, this network will probably undergo additional changes participating in the establishment at late fetal stages of a network functionally mature and developmentally comparable with that of the neonates as described previously in rat (Onimaru and Homma, 2002). These authors showed that burst pattern of respiratory motor nerve discharge, synaptic interactions, and voltagedependent membrane properties of inspiratory neurons changed drastically between E19 and E20. It is reasonable to

natal maturation of GABAergic inhibitory transmission (Ritter and Zhang, 2000). First, we have identified a bilateral rhythm generation site spatially restricted in a region ventral to the nucleus ambiguus, the activity of which is preserved in a transverse slice (Smith et al., 1991). Second, rhythm generation is concomitant to establishment of NK1R immunoreactivity in this region (Gray et al., 1999). Third, glutamatergic transmission through AMPA/kainate receptors conditions rhythm generation (Smith et al., 1991; Koshiya and Smith, 1999). Fourth, SP and DAMGO exert respective excitatory and depressing neuromodulatory influences on the rhythm generated (Gray et al., 1999; Janczewski et al., 2002; Manzke et al., 2003; Mellen et al., 2003), although the level of $\mu$-opioids and NK1 receptors expression might not be fully developed at this stage (Pagliardini et al., 2003; Kivell et al., 2004). Moreover, the onset of respiratory activity in mouse embryo during E15 corresponds to the developmental stage at which fetal movements become detectable (Suzue, 1994; Abadie et al., 2000). In keeping with the shorter gestational period of mice compared with rats, mouse developmental time E15 probably corresponds to rat E17 (Viemari et al., 2003), when formation of the respiratory rhythm generator is completed and begins to drive respiratory-like activity and fetal breathing movements (Di Pasquale et al., 1992; Greer et al., 1992; Kobayashi et al., 2001; Pagliardini et al., 2003). think that similar changes will occur also for the respiratory neural network of mice between E17 and E18.

The other neuronal group, the pFRG (Onimaru and Homma, 2003; Onimaru et al., 2004), contains neurons that discharge during the preinspiratory phase and that are synaptically connected to neurons of the PBC (Takeda et al., 2001; Janczewski et al., 2002; Mellen et al., 2003). Interestingly, two recent studies from Onimaru and Homma performed in rat showed (1) that neurons exhibiting a preinspiratory discharge could not be found before the developmental stage E19 (Onimaru and Homma, 2002) and (2) using optical recordings in embryonic rat brainstem-spinal cord preparations that the $\mathrm{pFRG}$ might not be functional before E19 (Onimaru and Homma, 2005). It will be of particular interest to examine whether, also in the mouse embryo, the pFRG might serve as a rhythm generator at later developmental stage than the PBC.

\section{The HF generator does not derive from}

LF-producing neurons

The presently described appearance of the HF generator at E15 probably dates, in the mouse hindbrain, the time when local networks and underlying specific connections begin to individualize, contributing to emergence of functional specialization. Interestingly, E15 is also the developmental stage when the imma- 
ture spinal network segregates into multiple functional networks in the spinal cord (Yvert et al., 2004). Therefore, at this stage, mature circuits may differentiate at the expense of larger primordial neuronal assemblies (Fenelon et al., 1998).

In the chick embryo, the emergence of $\mathrm{HF}$ activity proceeds by a progressive incorporation of HF bursts after a LF burst to form an episode of activity, so that HF generation is tightly linked to preexisting LF activity (Fortin et al., 1994; Coutinho et al., 2004). This is not the case in the mouse, in which LF interburst intervals initially devoid of any noticeable organized activity become during E15 at once filled by recurring $\mathrm{HF}$ bursting activity. Hence, $\mathrm{HF}$ respiratory-like activity in mice and episodic activity in the chick probably follow diverging ontogenetic routes.

Manipulating electrical coupling and glutamatergic transmission was found effective in suppressing LF and HF generation mechanisms, respectively, but led in both cases to a reduction of the frequency of the spared activity. This suggested that LF and HF activity generations probably rely on neurobiological substrates differing by the electrical/chemical balance supporting excitatory transmission. This is probably reflected by the distinct kinetics of transients LF and HF calcium changes. However, we can rule out that the HF generator simply derives from a change of this balance within the population of LF-generating cells. Indeed, LF and HF activities are generated in nonoverlapping dorsomedial and ventrolateral territories and can coexist in the same preparation. Nonetheless, the ventrolateral area is a target of LF propagating activity. Hence, there is a possibility for the existence of a LF activity-dependent control of the acquisition by neurons of the ventrolateral area of HF rhythmogenic properties and/or regulation of their commissural or dorsomedial projection pathfinding (Catalano and Shatz, 1998; Hanson and Landmesser, 2004).

The relative independence of LF and HF generating mechanisms is a favorable situation at E15 when LF activity is to rapidly disappear and HF rhythmic activity is to perform a vital functional role. Additional experiments are now required to investigate the converse possibility that downregulation of electrical communication through gap junctions and unapposed hemichannels that would result in weaning of LF activity may be modulated in a HF activity-dependent manner.

\section{The respiratory neural network differentiates from postmigratory neurons}

None of the respiratory rhythm generator characteristics so far tested have allowed us to identify a candidate population of migrating neural cells destined to form the HF generator before E15. In a previous study in the rat embryo, Pagliardini et al. (2003) similarly reported the lack of NK1+ cells in the PBC location before the onset of HF activity. Our observations at the earliest stage of respiratory activity indicate that there are no neurons exhibiting the PBC-like phenotype that are located between the germinative zone and the final ventrolateral location of the PBC.
This strongly supports the view that the entire set of PBC characteristics differentiate at E15 in postmigratory neurons. For example, there is a possibility that $\mathrm{NK} 1+$ respiratory cells may somehow segregate from the $\mathrm{NK} 1+$ ambiguus motoneuronal population lying immediately dorsal or that those motoneurons exert a local influence on respiratory cell differentiation. Future experiments using transgenic lines with impaired developmental programs of ventral motoneuronal and dorsal interneuronal progenitor domains should help identify the dorsoventral origin of the respiratory rhythmogenic modules. Calcium imaging, as performed in the present study, will be instrumental to directly appreciate associated functional and anatomical changes in mutant networks of the embryonic hindbrain.

\section{References}

Abadie V, Champagnat J, Fortin G (2000) Branchiomotor activities in mouse embryo. NeuroReport 11:141-145.

Ben-Ari Y (2001) Developing networks play a similar melody. Trends Neurosci 24:353-360.

Bennett MVL, Contreras JE, Bukauskas FF, Saez JC (2003) New roles for astrocytes: gap junction hemichannels have something to communicate. Trends Neurosci 26:610-617.

Blanco CE (1994) Maturation of fetal breathing activity. Biol Neonate 65:182-188.

Branchereau P, Morin D, Bonnot A, Ballion B, Chapron J, Viala D (2000) Development of lumbar rhythmic networks: from embryonic to neonate locomotor-like patterns in the mouse. Brain Res Bull 53:711-718.

Borodinsky LN, Root CM, Cronin JA, Sann SB, Gu X, Spitzer NC (2004) Activity-dependent homeostatic specification of transmitter expression in embryonic neurons. Nature 429:523-530.

Catalano SM, Shatz CJ (1998) Activity-dependent cortical target selection by thalamic neurons. Science 281:559-562.

Chang Q, Gonzales M, Pinter MJ, Balice-Gordon RJ (1999) Gap junctional coupling and patterns of connexin expression among neonatal rat lumbar spinal motor neurons. J Neurosci 19:10813-10828. 
Chub N, O’Donovan MJ (1998) Blockade and recovery of spontaneous rhythmic activity after application of neurotransmitter antagonists to spinal networks of the chick embryo. J Neurosci 18:294-306.

Cooke IR, Berger PJ (1996) Development of patterns of activity in diaphragm of fetal lamb early in gestation. J Neurobiol 30:385-396.

Cosmi EV, Anceschi MM, Cosmi E, Piazze JJ, La Torre R (2003) Ultrasonographic patterns of fetal breathing movements in normal pregnancy. Int J Gynaecol Obstet 80:285-290.

Coutinho AP, Borday C, Gilthorpe J, Jungbluth S, Champagnat J, Lumsden A, Fortin G (2004) Induction of a parafacial rhythm generator by rhombomere 3 in the chick embryo. J Neurosci 24:9383-9390.

DeVries JIP, Visser GHA, Prechtl HFR (1982) The emergence of behavior. I. Qualitative aspects. Early Hum Dev 7:301-322.

Di Pasquale E, Monteau R, Hilaire G (1992) In vitro study of central respiratory like activity in the fetal rat. Exp Brain Res 89:459-464.

Feller MB, Wellis DP, Stellwagen FS, Shatz CJ (1996) Requirement for cholinergic synaptic transmission in the propagation of spontaneous retinal waves. Science 272:1182-1187.

Fenelon VS, Casasnovas B, Simmers J, Meyrand P (1998) Development of rhythmic pattern generators. Curr Opin Neurobiol 8:705-709.

Fortin G, Champagnat J, Lumsden A (1994) Onset and maturation of branchio-motor activities in the chick hindbrain. NeuroReport 5:1149-1152.

Fortin G, Jungbluth S, Lumsden A, Champagnat J (1999) Segmental specification of GABAergic inhibition during development of hindbrain neural networks. Nat Neurosci 2:873-877.

Galli L, Maffei L (1988) Spontaneous impulse activity of rat retinal ganglion cells in prenatal life. Science 242:90-101.

Garaschuk O, Linn J, Eilers J, Konnerth A (2000) Large-scale oscillatory calcium waves in the immature cortex. Nat Neurosci 3:452-459.

Gray PA, Rekling JC, Bocchiaro CM, Feldman JL (1999) Modulation of respiratory frequency by peptidergic input to rhythmogenic neurons in the pre-Bötzinger complex. Science 286:1566-1568.

Gray PA, Janczewski WA, Mellen N, McCrimmon DR, Feldman JL (2001) Normal breathing requires pre-Bötzinger complex neurokinin-1 receptor-expressing neurons. Nat Neurosci 4:927-930.

Greer JJ, Smith JC, Feldman JL (1992) Respiratory and locomotor patterns generated in the fetal rat brain stem-spinal cord in vitro. J Neurophysiol 67:996-999.

Gust J, Wright JJ, Pratt EB, Bosma MM (2003) Development of synchronized activity of cranial motor neurons in the segmented embryonic mouse hindbrain. J Physiol (Lond) 550:123-133.

Hanson MG, Landmesser LT (2003) Characterization of the circuits that generate spontaneous episodes of activity in the early embryonic mouse spinal cord. J Neurosci 23:587-600.

Hanson MG, Landmesser LT (2004) Normal patterns of spontaneous activity are required for correct motor axon guidance and the expression of specific guidance molecules. Neuron 43:687-701.

Heath MJ, Lints TJ, Lee CJ, Dodd J (1995) Functional expression of the tachykinin NK1 receptor by floor plate cells in the embryonic rat spinal cord and brainstem. J Physiol (Lond) 486:139-148.

Horie M, Miyashita T, Watabe K, Takeda Y, Kawamura K, Kawano H (2000) Immunohistochemical localization of substance $\mathrm{P}$ receptors in the midline glia of the developing rat medulla oblongata with special reference to the formation of raphe nuclei. Brain Res Dev Brain Res 121:197-207.

Janczewski WA, Onimaru H, Homma I, Feldman JL (2002) Opioidresistant respiratory pathway from the preinspiratory neurones to abdominal muscles: in vivo and in vitro study in the newborn rat. J Physiol (Lond) 545:1017-1026.

Johnson SM, Smith JC, Funk GD, Feldman JL (1994) Pacemaker behavior of respiratory neurons in medullary slices from neonatal rat. J Neurophysiol 72:2598-2608.

Kandler K, Katz LC (1998) Coordination of neuronal activity in developing visual cortex by gap junction-mediated biochemical communication. J Neurosci 18:1419-1427.

Katz LC, Shatz CJ (1996) Synaptic activity and the construction of cortical circuits. Science 274:1133-1138.

Kiehn O, Kullander K (2004) Central pattern generators deciphered by molecular genetics. Neuron 41:317-321.

Kivell BM, Day DJ, McDonald FJ, Miller JH (2004) Developmental expression of $\mu$ and $\delta$ opioid receptors in the rat brainstem: evidence for a postnatal switch in $\mu$ isoform expression. Brain Res Dev Brain Res 148:185-196.

Kobayashi K, Lemke RP, Greer JJ (2001) Ultrasound measurements of the fetal breathing movements in the rat. J Appl Physiol 91:316-320.

Koshiya N, Guyenet PG (1996) Tonic sympathetic chemoreflex after blockade of respiratory rhythmogenesis in the rat. J Physiol (Lond) 491:859-869.

Koshiya N, Smith JC (1999) Neuronal pacemaker for breathing visualized in vitro. Nature 400:360-363.

Lieske SP, Thoby-Brisson M, Telgkamp P, Ramirez JM (2000) Reconfiguration of the neural network controlling multiple breathing patterns: eupnea, sighs and gasps. Nat Neurosci 3:600-607.

Manzke T, Guenther U, Ponimaskin EG, Haller M, Dutschmann M, Schwarzacher S, Richter DW (2003) 5-HT4(a) receptors avert opioid-induced breathing depression without loss of analgesia. Science 301:226-229.

Mellen NM, Janczewski WA, Bocchiaro CM, Feldman JL (2003) Opioidinduced quantal slowing reveals dual networks for respiratory rhythm generation. Neuron 37:821-826.

Milner LD, Landmesser LT (1999) Cholinergic and GABAergic inputs drive patterned spontaneous motoneuron activity before target contact. J Neurosci 19:3007-3022.

O'Donovan MJ (1999) The origin of spontaneous activity in developing networks of the vertebrate nervous system. Curr Opin Neurobiol 9:94-104

O’Donovan MJ, Landmesser L (1987) The development of hindlimb motor activity studied in the isolated spinal cord of the chick embryo. J Neurosci 7:3256-3264.

Onimaru H, Homma I (2002) Development of the rat respiratory neuron network during the late fetal period. Neurosci Res 42:209-218.

Onimaru H, Homma I (2003) A novel functional neuron group for respiratory rhythm generation in the ventral medulla. J Neurosci 23:1478-1486.

Onimaru H, Homma I (2005) Developmental changes in the spatiotemporal pattern of respiratory neuron activity in the medulla of late fetal rat. Neuroscience 131:969-977.

Onimaru H, Arata A, Arata S, Shirasawa S, Cleary ML (2004) In vitro visualization of respiratory neuron activity in the newborn mouse ventral medulla. Brain Res Dev Brain Res 153:275-279.

Pagliardini S, Ren J, Greer JJ (2003) Ontogeny of the pre-Bötzinger complex in perinatal rats. J Neurosci 23:9575-9584.

Peinado A (2000) Traveling slow waves of neural activity: a novel form of network activity in developing neocortex. J Neurosci 20:RC54(1-6).

Peinado A, Yuste R, Katz LC (1993) Extensive dye coupling between rat neocortical neurons during the period of circuit formation. Neuron 10:103-114.

Pena F, Parkis MA, Tryba AK, Ramirez JM (2004) Differential contribution of pacemaker properties to the generation of respiratory rhythms during normoxia and hypoxia. Neuron 43:105-117.

Ramirez JM, Quellmalz UJA, Richter DW (1996) Postnatal changes in the mammalian respiratory network as revealed by the transverse brainstem slice preparation of mice. J Physiol (Lond) 491:799-812.

Ramirez JM, Schwarzacher SW, Pierrefiche O, Olivera BM, Richter DW (1998) Selective lesioning of the cat pre-Botzinger complex in vivo eliminates breathing but not gasping. J Physiol (Lond) 507:895-907.

Ren J, Greer JJ (2003) Ontogeny of rhythmic motor patterns generated in the embryonic rat spinal cord. J Neurophysiol 89:1187-1195.

Ritter B, Zhang W (2000) Early postnatal maturation of $\mathrm{GABA}_{\mathrm{A}}$-mediated inhibition in the brainstem respiratory rhythm-generating network of the mouse. Eur J Neurosci 12:2975-2984.

Roerig B, Feller MB (2000) Neurotransmitters and gap junctions in developing neural circuits. Brain Res Rev 32:86-114.

Rossi FM, Pizzorusso T, Porciatti V, Marubio LM, Maffei L, Changeux JP (2001) Requirement of the nicotinic acetylcholine receptor $\beta 2$ subunit for the anatomical and functional development of the visual system. Proc Natl Acad Sci USA 98:6453-6458.

Rouach N, Segal M, Koulakoff A, Giaume C, Avignone E (2003) Carbenoxolone blockade of neuronal network activity in culture is not mediated by an action on gap junctions. J Physiol (Lond) 553:729-745.

Saint-Amant L, Drapeau P (2001) Synchronization of an embryonic network of identified spinal interneurons solely by electrical coupling. Neuron 31:1035-1046.

Smith JC, Ellenberger HH, Ballanyi K, Richter DW, Feldman JL (1991) Pre- 
Botzinger complex: a brainstem region that may generate respiratory rhythm in mammals. Science 254:726-729.

Spitzer NC, Root CM, Borodinsky LN (2004) Orchestrating neuronal differentiation: patterns of $\mathrm{Ca}^{2+}$ spikes specify transmitter choice. Trends Neurosci 27:415-421.

Stornetta RL, Rosin DL, Wang H, Sevigny CP, Weston MC, Guyenet PG (2003) A group of glutamatergic interneurons expressing high levels of both neurokinin-1 receptors and somatostatin identifies the region of the pre-Bötzinger complex. J Comp Neurol 455:499-512.

Suzue T (1994) Mouse fetuses in late gestation maintained in vitro by transplacental. Neurosci Res 21:173-176.

Takeda S, Eriksson LI, Yamamoto Y, Joensen H, Onimaru H, Lindahl SGE (2001) Opioid action on respiratory neuron activity of the isolated respiratory network in newborn rats. Anesthesiology 95:740-749.

Thoby-Brisson M, Ramirez JM (2001) Identification of two types of inspiratory pacemaker neurons in the isolated respiratory neural network of mice. J Neurophysiol 86:104-112.

Thoby-Brisson M, Telgkamp P, Ramirez JM (2000) The role of the hyperpolarization-activated current in modulating rhythmic activity in the isolated respiratory network of mice. J Neurosci 20:2994-3005.

Thoby-Brisson M, Cauli B, Champagnat J, Fortin G, Katz DM (2003) Ex- pression of functional tyrosine kinase B receptors by rhythmically active respiratory neurons in the pre-Bötzinger complex of neonatal mice. J Neurosci 23:7685-7689.

Tsunekawa N, Arata A, Obata K (2005) Development of spontaneous mouth/tongue movement and related neural activity, and their repression in fetal mice lacking glutamate decarboxylase 67. Eur J Neurosci 21:173-178.

Viemari JC, Burnet H, Bevengut M, Hilaire G (2003) Perinatal maturation of the mouse respiratory rhythm-generator: in vivo and in vitro studies. Eur J Neurosci 17:1233-1244.

Wang H, Stornetta RL, Rosin DL, Guyenet PG (2001) Neurokinin-1 receptor-immunoreactive neurons of the ventral respiratory group in the rat. J Comp Neurol 434:128-146.

Weissman TA, Riquele PA, Ivic L, Flint A, Kriegstein AR (2004) Calcium waves propagate through radial glial cells and modulate proliferation in the developing neocortex. Neuron 43:647-661.

Yvert B, Branchereau P, Meyrand P (2004) Multiple spontaneous rhythmic activity patterns generated by the embryonic mouse spinal cord occur within a specific developmental time window. J Neurophysiol 91:21012109. 